\title{
Urban Landscape: Essay of Definition of an Algerian Vernacular Style among Students in Architecture
}

\author{
Nabil Roubai Chorfi \\ Department of Civil Engineering and Architecture, Abdelhamid Ibn Badis University, Mostaganem, Algeria
}

Received February 15, 2021; Revised April 18, 2021; Accepted June 20, 2021

\section{Cite This Paper in the following Citation Styles}

(a): [1] Nabil Roubai Chorfi, "Urban Landscape: Essay of Definition of an Algerian Vernacular Style among Students in Architecture," Civil Engineering and Architecture, Vol. 9, No. 4, pp. 1257-1267, 2021. DOI: 10.13189/cea.2021.090427.

(b): Nabil Roubai Chorfi (2021). Urban Landscape: Essay of Definition of an Algerian Vernacular Style among Students in Architecture. Civil Engineering and Architecture, 9(4), 1257-1267. DOI: 10.13189/cea.2021.090427.

Copyright $\odot 2021$ by authors, all rights reserved. Authors agree that this article remains permanently open access under the terms of the Creative Commons Attribution License 4.0 International License

\begin{abstract}
This research is carried out with Algerian architecture students in a didactic framework which aims to demonstrate the process of defining architectural bias in the Algerian and, by extension, Mediterranean urban landscape. Many Algerian cities no longer have their character despite regional, climatic and socio-cultural particularities. The old urban fabrics are gradually transformed into precarious housing zones, concerned by a policy of resorption which disintegrates them, annihilating any historical anchoring in a style that one could qualify as Mediterranean or Algerian. It is in this environment of physical and intellectual impoverishment that we tried to understand the cognitive process that leads students to refer to this or that criterion as part of the expressionist vocabulary of Algerian architecture. Using an anchored theorizing approach, we have built up a corpus within the design learning workshop, thus resulting in a framework of formalization criteria of an architectural, spatial, colourimetric or sometimes functional order. Thus, some admit the local expression only for cultural or religious buildings while others do not conceive of an Algerian style without the presence of symbolic and often stylized or modernized artefacts, such as the trellis or the arcade. Attitudes are far from uniform and consensual.
\end{abstract}

Keywords Algerian Style Vernacular Didactic approach Reference Identity

\section{Introduction}

This research conducted with Algerian architecture students in a didactic framework which aims to demonstrate the process of defining architectural bias in the Algerian urban landscape and, by extension, the Mediterranean.

Many Algerian cities have lost their cachet due to unrestrained and uncontrolled self-construction or the mass production of collective housing conditioned by standardized specifications. This is done despite regional, climatic and socio-cultural particularities. The appearance of buildings often depends on the autocratic demands of decision-makers.

Subsequently, the old urban fabrics are gradually transformed into areas of precarious housing, concerned by a policy of absorption which disintegrates them, annihilating any historical anchoring in a style which one could qualify as Mediterranean or Algerian.

It is in this environment of physical and intellectual impoverishment that we have tried to get students to redefine the local style. Our goal being, beyond identifying this formal choice, to understand the cognitive process which leads the students to reference this or that criterion as being part of the expressionist vocabulary of Algerian architecture.

Using a grounded theory approach, we have built up a corpus of workshop observations recorded in logbooks, various student productions as well as selected reference documents and transcripts of formal and informal discussions. The well-known scholars Strauss and Corbin [1] define Grounded Theory as "theory that was derived from data, systematically gathered and analysed through the research process. In this method, data collection, analysis, and eventual theory stand in close relationship to one another."

We have thus arrived at a framework of formalization 
criteria of an architectural, spatial, chromatic or sometimes functional order. Thus, some admit the local expression only for cultural or religious buildings while others do not conceive an Algerian style without the presence of symbolic and often stylized or modernized artefacts such as the cloister or the arcade. Attitudes are far from uniform and consensual.

The results are unmistakable: the defined style definitively excludes any purist reference to relate entirely to a theoretical vision of what should be the architectural expression of Algeria. The existing urban landscape is rejected by the students in favour of an idealized vision, relating to three main references: Cultural through an Arab-Moorish style with stylized forms, Landscape through a falsified Mediterranean style and finally, Referential through the return to an architect or a movement considered to be of reference.

\section{Observing the Style Being Created}

The initial definition of architecture dictated by the Roman architect Vitruvius in his treatise 'De architectura', via his famous triad: firmitas (solidity), utilitas (convenience) and venustas (beauty) does not exhaust the subject and its complexity. A complexity exacerbated by the didactic situation, when added to the faculty of creating and conceiving, that of transmitting and communicating knowledge and disciplinary competence.

It is by observing the future architects in the process of acquiring know-how that we measure all the difficulties in identifying certain mechanism linked to creation, composition and stylistic bias. Observing the development of the architectural bias requires an incursion into the environment concerned without any form of distancing or delay.

Designing architecture is also a complex process, which implies, beyond its formatting, taking into account of multiple factors of a physical, psychological, sociological, historical, cultural, economic, ecological nature... Faced with this reality, rationalism, deterministic sciences and the simplifying processes inherited from the seventeenth century are no longer suited to our way of thinking about architecture [2].

As a teacher, the continuous relationship with the students in full creative activity constitutes a confrontation with the complex and dense expression of a culture of so many emerging personalities. These personalities express themselves through their artefacts and their discourse on artefacts, yet it is through a conscientization of the links between the entities that define the student project that we will be able to identify the phenomenon of the emergence of style. These entities are the student and his project, the discourse on the project, but also the discourse on the process, in other words, the 'metacommunication' of the project.

Observations focused on the levels where students are most sensitive to emerging architectural expressions in search of their own identity. We have thus avoided the first year when architectural design remains in basic forms and the Master levels where architectural creation often tends to manifest itself through a universalist expression, drawing on the great personalities of international architecture.

Generally, the second- and third-year student architects questioned before this survey show more a feeling of belonging to pan-Arab unity with a background of common Islamic culture, than to entirely other components such as Africanism, a Mediterranean civilizational history or even the colonial link with France. This last component, although present, is the subject of sensitive debates within society.

\subsection{Grounded Theory in Practice}

Our methodological orientation aims more at the behaviour of the students concerning the determination of the style in the design than the modelling of the process which underlies this formalization. To this end, Grounded Theory (GT) is a research methodology that focuses on the modelable interactions that manifest themselves through patterns of social behaviour within a specific group [3]. By theorizing, we are certainly not targeting the theoretical model, but rather the process to arrive at an understanding of new phenomena.

Since we do not rely on a set of assertions regarding the formalization of stylistic bias in the design process of students, the grounded theory applied to our qualitative research will strongly link aspects of conceptualization and theorizing [4].

\subsubsection{Participant observation}

In terms of information gathering, we have noticed in recent years that participant observation, formerly limited to the fields of anthropological and sociological studies, is taking on a more democratic appearance by being extended to other qualitative approaches, in particular in didactics.

Participant observation allows researchers to scrutinize activities in their natural environment while evolving with the actors of these activities. It provides the context for the development of sampling guidelines and interview guides [5].

We will define our participant observation as a process of reporting within the architectural design learning workshop. Being accepted by the group in order to push its members to remain natural is easy because of our relationship with the environment; we stayed in our teaching posture while trying to have a 'meta-observation' of the situation. Fieldwork involves "active looking, improving memory, informal interviewing, writing detailed field notes, and perhaps most importantly, patience" [5]. 


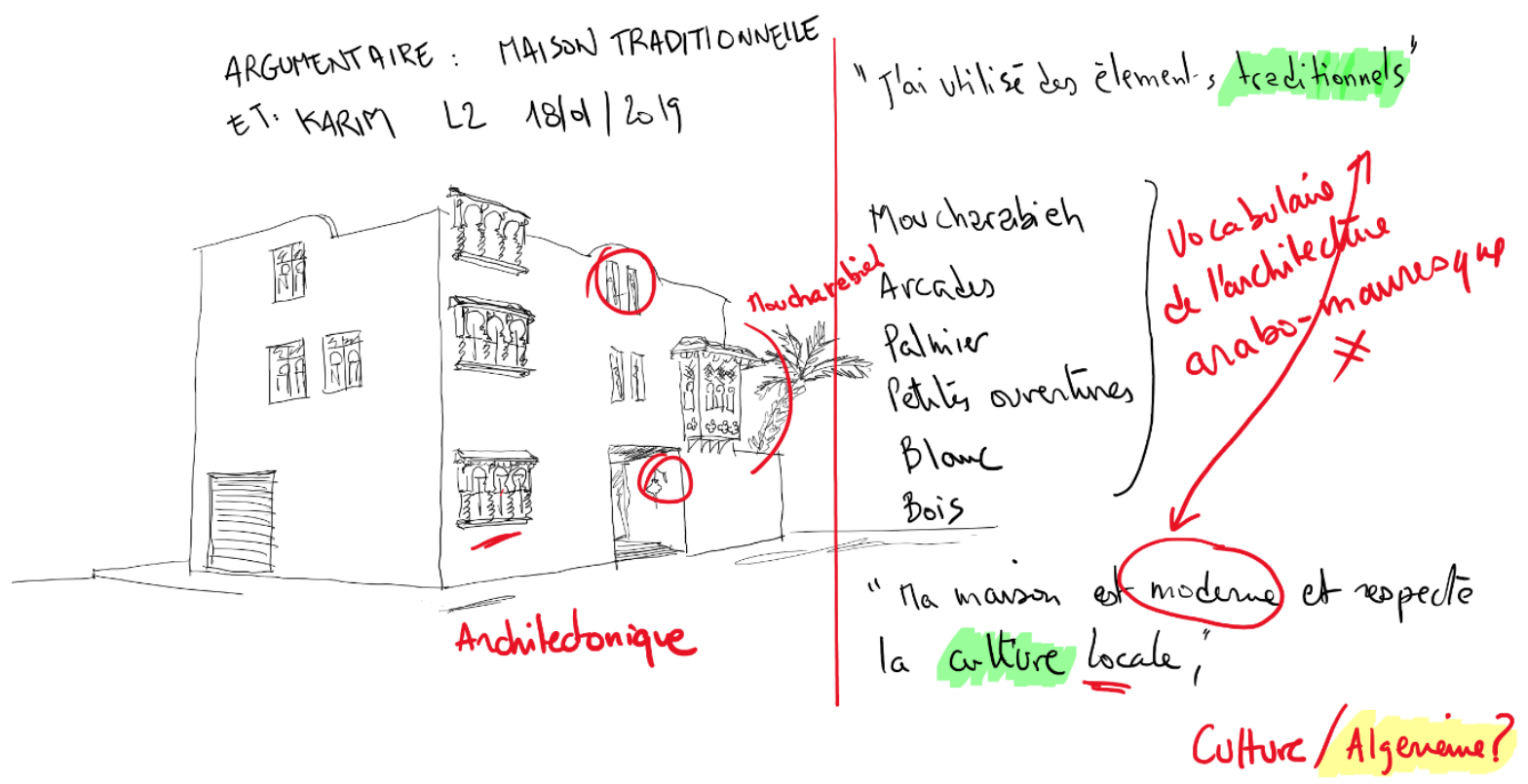

Figure 1. Page from our diary illustrating a note-taking during a discussion session with the students around their projects. This is an initial phase of so-called "open" coding (in red).

In grounded theory, sampling is not determined at the outset, but rather an emerging feature of theory that continues until saturation of the coded categories is reached. Subsequently, our observation sample is large, made up of meetings included in our regular practice of workshop teaching. We did not develop a selective method but we looked at two years of observation while we were concerned with the teaching of the second year which addresses the habitat. To this, we have added more prolonged observations and notes taken over several years concerning the end of studies projects of outgoing students.

\subsubsection{A Logbook for Observation}

The operation goes beyond observation; it includes spontaneous conversations, questionnaires, interviews and discreet forays linked to didactic techniques specific to the teaching of architecture. However, most anthropologists placed in a participatory observation situation must maintain a sense of objectivity across distance [6].

Information gathered from various techniques is recorded. A diary or a logbook is almost always used to keep records of observations and conversations, see Figure 1. Moreover, we have relied on specific software for the qualitative analysis of large bodies of textual, graphical, audio and video data. Qualitative data analysis strategies are not compatible with stereotypical approaches. We have opted for a non-deterministic methodological approach in order to get closer to the work of analysis apart from any mechanical action. [7].

\subsection{Data Collection and Results}

According to Creswell [8], the choice of an anchored theorizing methodology makes it possible to develop a theory based on field data through the opinions of the participants. While drawing inspiration from sociology, it is a question of studying a process, an action or an interaction involving many individuals. The data analysis strategy is then done by open, axial and selective coding, ultimately resulting in a report illustrated by a figure.

If in our methodological approach, the collected data are evaluated by applying different coding methods as a basic process, we will only focus here on the final phase of the analysis for the sake of brevity. It should be known that the coding in the methodology of the grounded theory aims at conceptual abstraction by attributing general concepts (codes) to singular incidences in the data, see Figure 2. This is a fragmented process with indistinguishable phases and a heavy and laborious process for the researcher, especially in its initial phase (open coding), the essential elements of which raise awareness questions and constantly compare data and codes [9].

We operated by "open coding", by dissecting and defragmenting the analyzed material into a multitude of codes to then bring them together by "axial coding", in the form of categories revealing concepts. Thus, we will be able to illustrate this by grouping together certain codes relating to architectural choices (arch, mashrabiya, column, white, palm tree, cupola, basin ...) to a category expressed by the Arab-Moorish reference.

However, we must go beyond the linguistic approach in this type of analysis to focus on the concepts. For example, we discovered that the codes (cultural references, traditions, modernity, vernacular, Islam, minimalism, monumentalism, ostentation ...) had, despite antinomic semantic characteristics, a common axis of categorization: the indeterminacy of belonging. 


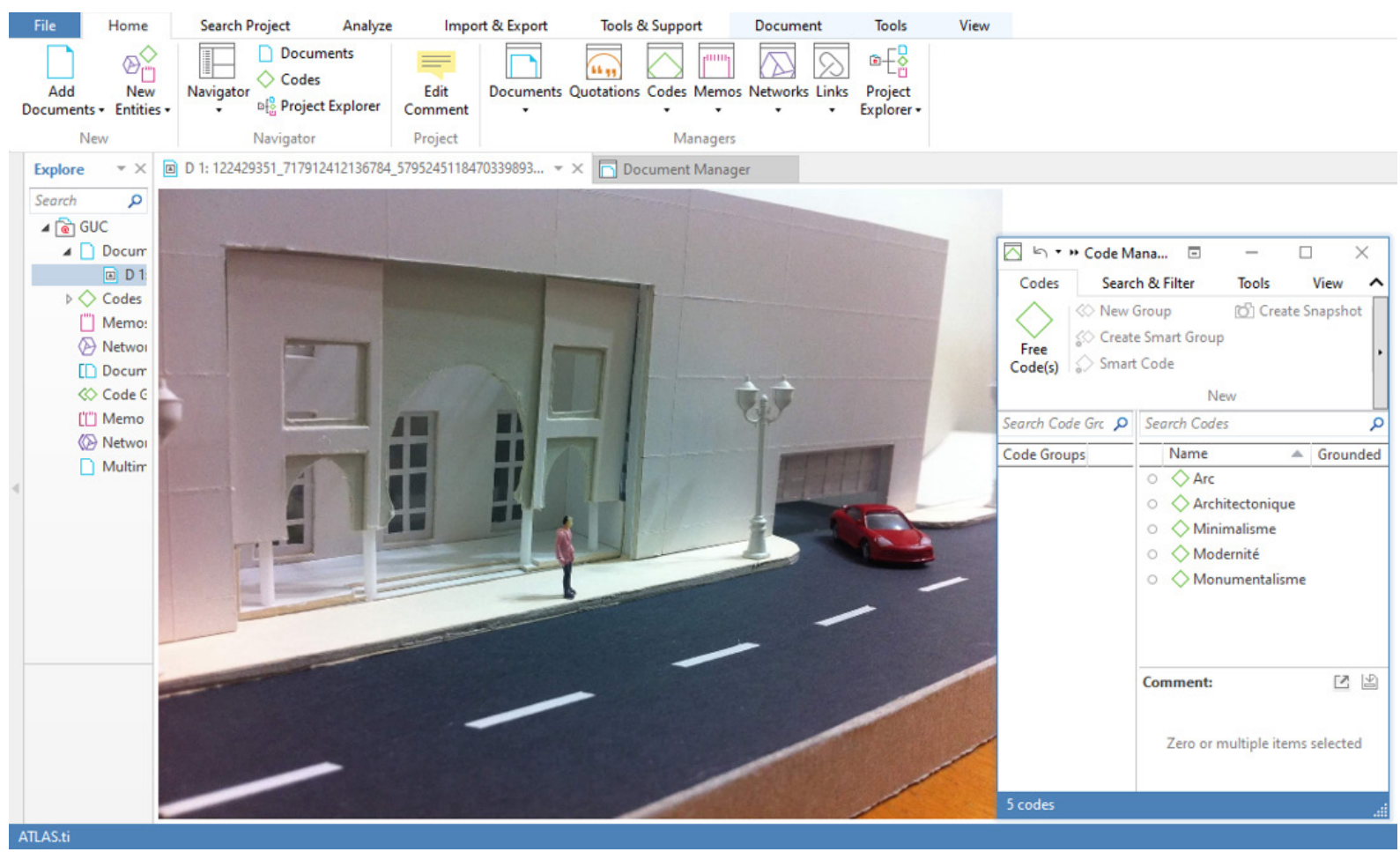

Figure 2. Illustration of software processing in the open coding phase. Second-year student project: facade treatment of a house for single-family living on a model [10]

The relevance of the codes developed, generally occurring by coherence and rootedness, allows us to pass to the phase of selective coding. It is about a process of integration of the codes having emerged while releasing a central scenario coming to explain what occurs in our field of study. The single, central and structural category will allow us to identify our theory.

\subsubsection{The triadic structure of the process}

A triadic structure appears by processing the data from the participant observation, relating three postures for the students in the phase of defining the architectural bias. This structure is paradigmatic - in the sense of grounded theory - at the very moment when we notice a saturation of the phenomenon, that is to say, a status quo of behaviour vis-à-vis the search for references. This structure links or opposes three influences that appear systematically among the students as justifications for the stylistic choices and the spatial and architectonic approach of the proposed artefacts.

It is first of all the cultural influence of ethnic and religious affiliation akin to Arab-Moorish architecture. The occurrences that stand out are directly linked to the elements of identification of the Arab-Moorish style of Andalusian influence (specific decorations, landscaping of gardens) as well as certain elements of oriental architecture sometimes contradictory with the history of Algeria or its climate (mashrabiya, malqaf, iwan).

Second, the geographical influence linked - curiously to disparate architectures, some local (Mozabite architecture, casbah) and others certainly Mediterranean but rather distant (white houses of the Cyclades, stereotypes of Mediterranean architecture). Finally, the scholarly influence through the use of recognized and personified architecture (the works of Fernand Pouillon, the influence of Andre Ravereau, the aura of Hassan Fathy). In Figure 3 below, we illustrate the final paradigm resulting from a relation of eleven super-codes linked to each other by the three codes of higher category. It is the latter that will be developed in this article.

The tendency to mix styles is constant in official architecture in Algeria where state buildings are mostly called "Arab-Moorish" with rigid prescriptions dictated to designers: bring together architectural elements reminiscent of Islamic culture, using arches and domes, use cornice tile and earthenware for the base. However, architects have long translated this request by a syncretic approach combining without research everything that relates directly or indirectly to a local cultural expression. This by using, falsely, geographically distant but culturally marked elements such as mashrabiyas, malqafs and iwans. 


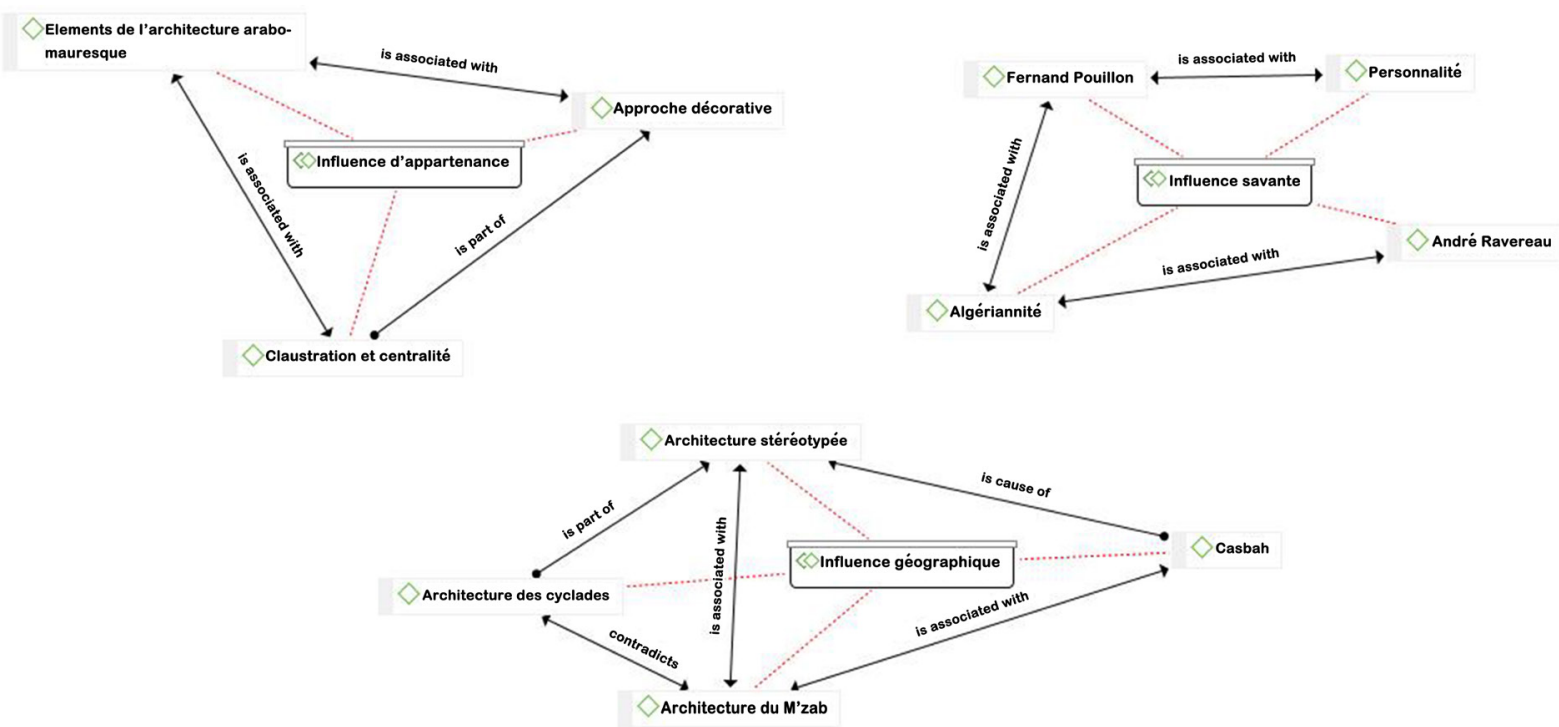

Figure 3. Graphic representation of the paradigms rooted in our approach via Atlas.ti. The codes are expressed in French, the institutional language of the home university

\subsubsection{Proceedings}

Students generally proceed by association of ideas, and in the case of architectural composition by combination of architectural elements. Figure 4 below summarizes the general structure of behaviours vis-à-vis the axes used in the formalization of the style as we identified them through a long process of note taking and coding according to the method previously explained. Something prohibited when it comes to absolute creation, as soon as it comes to opting for a stylistic bias, the shortcuts appear in the references option.

For example, when the student reflects on his identity belonging, he will exploit the architectural elements which recall his Arab-Islamic or Berber identity. He will then draw from the panel of elements that represent Arab-Moorish architecture of all kinds. It sometimes happens to see elements of Persian or Andalusian architecture grafted onto a composition, but more often it is the classic arches, arcades, cupolas, musharabys, arabesques and malqafs.

Iteratively, when the student reflects on the geographic context or when, during discussion sessions with the teacher, he is taken back for his lack of contextualization, he orients himself on local elements. He will then add to the fragmented elements a semblance of unity through geographical and climatic references. The patio house, the Mozabite or Kasbah architecture, the Kabyle house or even the Mediterranean house in the broad sense then form a unifying base.

This state of affairs is not specific to the students observed because we noted that they justified this process by relying on the rare theorists and practitioners of Algerian architecture who still have an audience with academics. However, these architects themselves drew their references from a mixture of local and less local architectural elements.

But then, after this observation, the question that arises is why the process of formalizing the bias invariably takes this shape? what are the levers for its formalization? How to intervene in the didactic framework to compensate for the rigidity of this process?

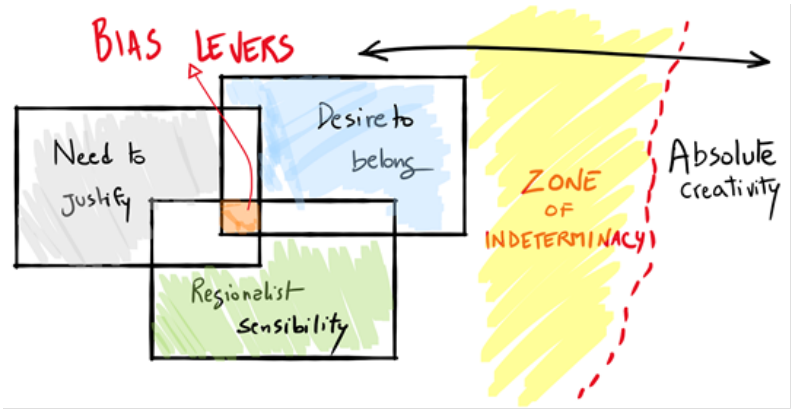

Figure 4. Levers of bias, a balanced mix between the desire to belong to a culture, the response to climatic and geographic justifications and a scientific justifying reference

\section{Levers that Generate Bias among Students}

Functioning, it is imperative to synthesize it in a static diagram to freeze it at a precise moment, see Figure 5. This is how the following figure attempts to summarize what we have called "levers" conditioning the behaviour of students vis-à-vis the referenced creation, in other words, the bias.

These levers appear, apart from the schematic appearance, as real lever arms in the physical sense. As we explore the schema, we will notice that the choices regarding references exacerbate the orientation of belonging and vice versa.

Thus, it is the universalist posture, that is to say, a 
choice of contemporary architectural expression devoid of heritage traces, which will push the student to self-referencing, mainly relying on his capacity to "invent". By symmetry, it is the desire to belong to a culture and to express it, in other words by "esprit de corps", that the student will tend towards a hetero-referencing drawing on a large panel of stereotypical architectural elements.

Finally, let us note that esprit de corps is a collective behaviour marked by the search for identifiable and appropriate resources, while the universalist posture remains personal and will draw on the specific expressions of each student. The artefacts are affected by it, between uniformity and exuberance of features on one side and diversity and sobriety of features on the other.

\subsection{Shortage of References}

Pages Madrigal [11] defines cultural heritage as a sum of palpable objects and intangible attributes inherited from past generations. He cites Logan [12] in explaining that the legacies of past generations constitute a heritage produced by a process of selection by society.

The poverty of references observed in the attempt to define an Algerian style, vernacular in the first sense of indigenous and exclusive without falling into traditionalism, sends us back to a state of affairs. That of a neglect of architectural thought in a country which has difficulty in safeguarding its material and immaterial heritage, which sees its old buildings disintegrating in favour of urban extensions with a neutral, impersonal and qualityless face.

The attempts to rehabilitate colonial centres through facades renovation operations carried out for only a few years have not succeeded in re-establishing a whole section of history knowingly ignored since independence (1962). The acceptance of an identity-based Algerian architecture made up of all facets of history, including the French period, has struggled to impose itself in the imagination of Algerians. They then refer to older traces, unfortunately already severely degraded.

\subsubsection{Synchretism and inflation}

The least that we can say by observing the Algerian architects at work is that the lack of references is obvious when we place ourselves in a perspective of actualization. This is all the more felt when immersed in the training of students, we find a mixture of genres justified in different ways. Sometimes it is a desire to belong to a culture, a belief or a viscerally Algerian history. Sometimes it is the duty of memory that refers to outstanding works that have withstood the ravages of time. Sometimes it is a question of basing one's daring on well-known intellectual tutors through their productions and their reflections. They wrote and thought about Algerian architecture and town planning, they left traces. Paradoxically, they are predominantly Western: André Ravereau, Fernand
Pouillon, Jean-Jacques Delluz.

However, can we raise a contradiction between the syncretism of composition and the assertion of oneself in formal expression? This is to differentiate syncretism from visual blasphemy [13].

The vernacular allusion flanked to the architecture that one could qualify as Algerian, Maghrebian or Mediterranean is necessarily akin to a populist vision. The notion of "popular architecture" therefore applies to a branch of architecture that favours the constant and ethnically defined local traditions of the know-how of the builders and reproduces patterns, developed over the centuries, thus safeguarding the traditional profile architectural and landscape models.

The world staged by the student must be able to create its realities, realities that emerge during discussions around the artefacts submitted to the teacher's expertise. The expression of style is exacerbated by the use of heterogeneous references that the student tries to convey, not by a reasoned approach, but by an inflation of means of identification.

\subsubsection{The imaginary, a substitute for culture}

According to Ylimaula [14], style is not a preconceived category, but it evolves from the artefact and reveals the nature of the work. The work allows the style to occur and the style expresses artistic truth. The creation of a work of architecture is connected with preservation: a creative spark had been received and is preserved in the work.

Jean-Jacques Deluz, Swiss architect and urban planner living in Algiers since 1956 having worked and taught there, talks about the need to contextualize urban issues despite the heritage perspective: "[...] Knowledge of the present and knowledge of the past are inseparable when it comes to urban and architectural qualities because the only qualitative references we have on this level are that of the past: in Algiers, the Casbah and the colonial town. But each of these references cannot serve as a model, being the product of a company in its time. It is up to us, through the broadest possible knowledge, to know how to integrate these references into current issues" [15].

In the absence of a built environment rich in historical references and in the more flagrant absence of a system of cultural beliefs allowing them to adhere to a specific vision of their environment, the students have their faculties of imagination. It is therefore often tinged with preconceptions that the artefacts, catalysts for a whole panoply of identifiable architectural elements, are presented as the fruit of a viscerally Algerian expression.

This diagram corresponds to a unifying scheme which takes the general observations without considering the particularities of each student. The object of our research being, precisely, is to arrive at a generalist behavioral model which considers the student only in relation to his belonging to the place and to the culture of this place and this moment. 


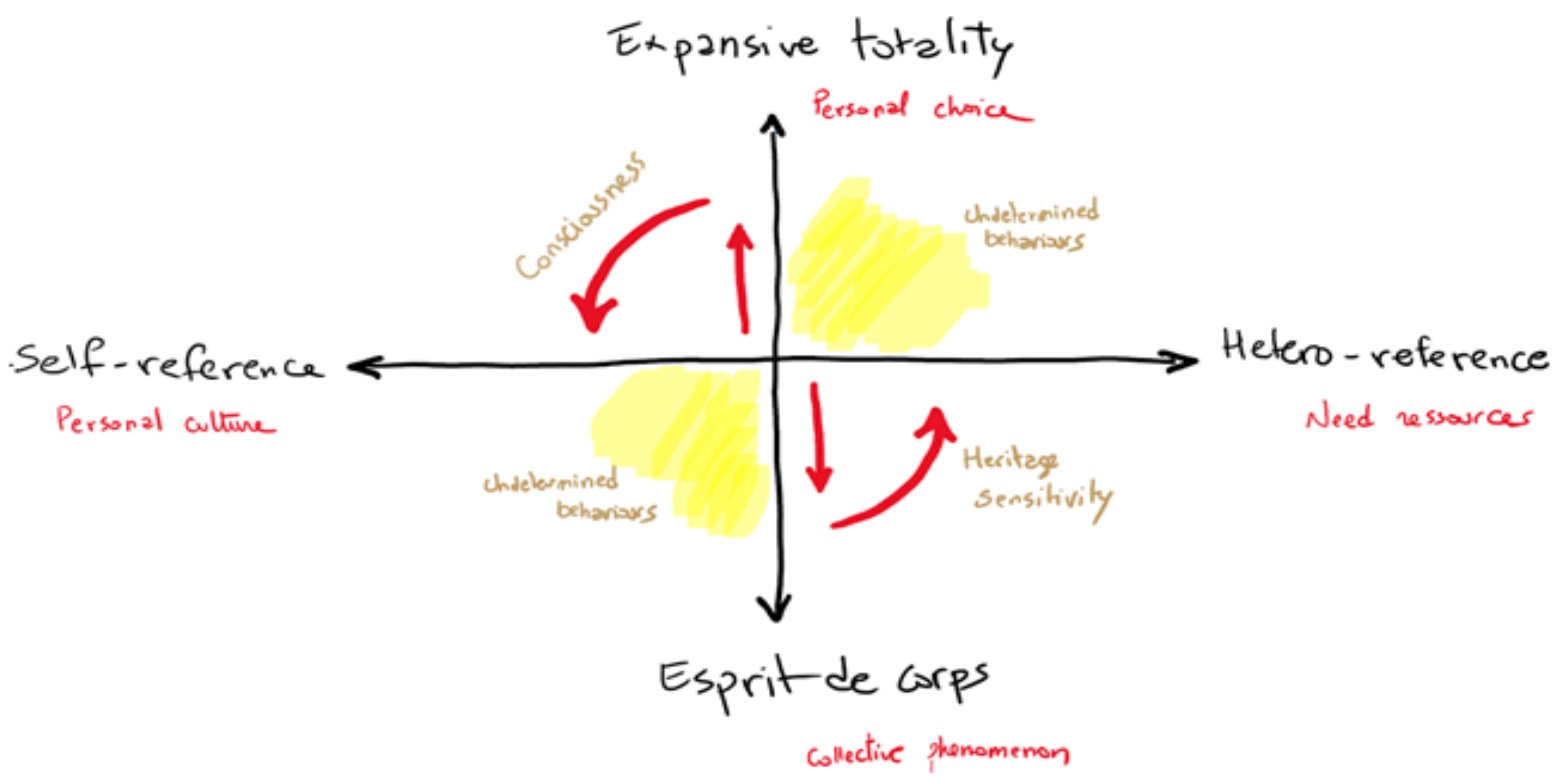

Figure 5. Summary diagram, the levers that generate the architectural bias among the students observed. Between personal culture and surrounding influences, between the desire to belong and the need for universality.

\subsection{Reconstruction and Atavism}

In this part, we will approach from a more factual point of view the iterative and systematic behaviours observed in the students, in the light of the levers generating the bias developed above.

The students tend to have an atavistic approach compensating for the shortcomings of local cultural anchoring by a reconstructive approach based on conceptual biases. They will thus proceed by an aesthetic approach on the classic elements, forcing the conceptualization to the detriment of the use, to erase the functional peculiarities in favour of the appearance and the belonging to an agreed code.

Mediterranean, Arab-Berber or even Muslim atavism is felt through a systematic search for architectural invariants to 'freeze' time and establish the culture of the project presented. In hushed words, without open and assumed declarations, the architectural bias takes on the appearance of reconstruction where each reference to the past, place or thought, is reformulated in projects with a contemporary and spontaneous feel.

All the studied examples confused with the accounts of the students that we have recorded in the log-book use the same arguments: The geographical origin of the architectural element borrowed is subservient to its symbolic nature.

The examples that we present in this article systematically represent this mixture of style and heterogeneous elements, yet the speeches of their designers remain constant and put forward a desire for cultural unity. Eclecticism thus emerges in the speeches of the students as a methodological process of enrichment and consolidation of the bias.

\subsubsection{Conceptualized Arab-Moorish architecture}

We can consider architectural syncretism as a process of balancing and merging in the designer, of mixing or integrating religious activities and symbols, traditions, cultural practices and adaptation to the environment. From a formal point of view, this process involves abandoning descriptive and prescriptive design in favour of speculative representation. The proposed forms are allusions to the reference elements of Arab-Moorish architecture translated by manipulable abstractions.

This is not without asking ethical questions: when a space must materialize a culture, the designer can hardly do without questioning the values that the artefact will have to bear. Belonging requires to be concretized, given to see through architecture, its abstract reality materialized. The space must embody this content. This set of mutual implications corresponds to that of symbolic functioning: by concretely representing a style - the building assigned to this representation itself becomes a symbol.

As we can see in Figure 6, the symbolic weight of the Arab-Moorish is all the more supported that it is expressed in the student in a refined version, signifying his displacement from symbol of history to symbol topical. It is no longer a question of manipulating frozen elements copied from old architectures, but of reviving a unifying language.

\subsubsection{The wide Mediterranean style}

Belonging to a Mediterranean sphere that goes beyond ethnic and religious filiation is a subject present in the debates of the students around their projects. They do not reject the idea of a unifying and evolving style, as an alternative solution to the radicalism of the Arab-Moorish bias. 

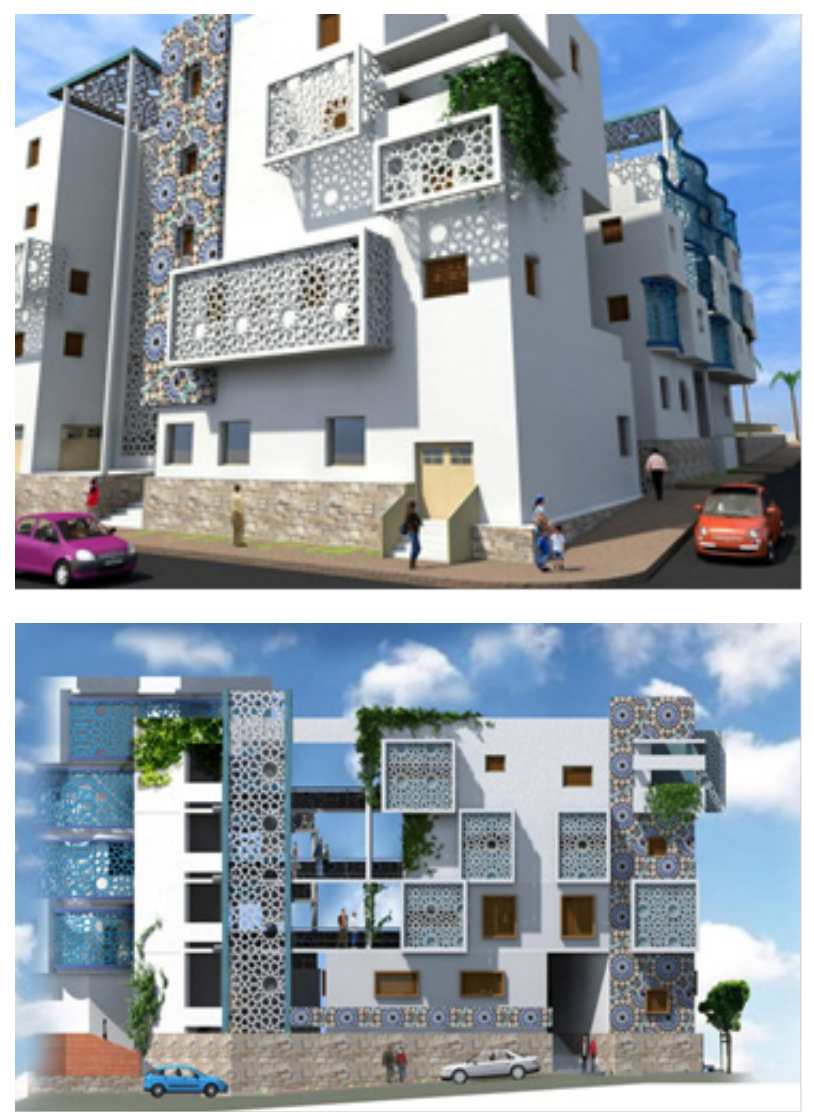

Figure 6. End of studies project entitled "Discourse on the concept of Mediterranean habitat" by BENMALTI Asmaa (C) 2011 https://issuu.com/linamess/docs/portfolio

For the students, it is about trying to minimize the ideological impact induced by stylistic choices sometimes perceived as radicalise. The aesthetics of a musharabya only temporarily impact the reception of the stylistic message distilled by the student, before there is a critical reaction to the impertinent use of an offbeat architectonic. Especially since the Algerian authorities have previously made an abusive use of the Arab-Moorish symbolism in monumental works, as a way of dictating a symbolic style of the state.

However, this geographic orientation would tend to erase local disparities and particularities in favour of a stereotypical and magnifying vision. Students then tend to identify real points in common between the different architectures of the Mediterranean basin while translating them in a simplifying way. They tend above all to extrapolate the local Saharan architectures, notably the precious Mozabite heritage, by popularizing it in attempts at universalization, see Figure 7.
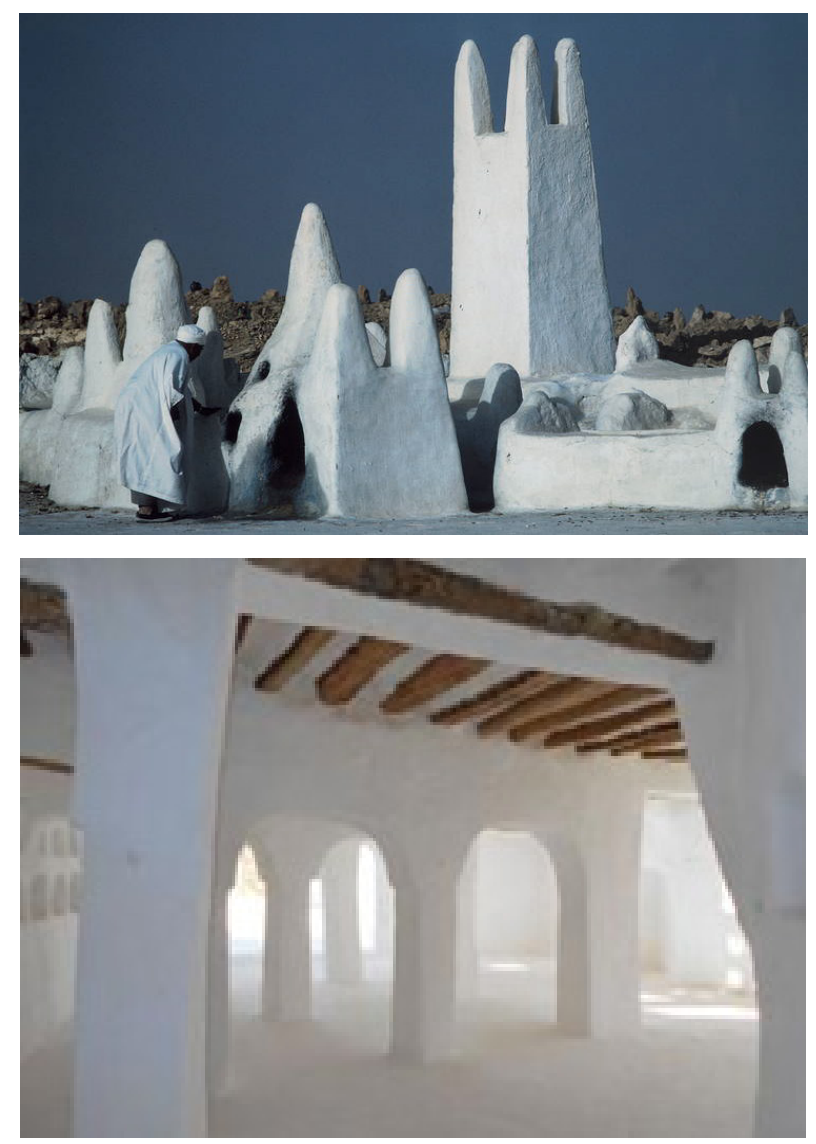

Figure 7. (a) City of M'Zab, UNESCO (c) / (b) Mausoleum of Sidi Brahim - El Atteuf, 2011 C Mohamed Ladaoui Benferhat.

\subsubsection{Fernand Pouillon's idealized heritage}

An increasingly recognized architect and writer, Fernand Pouillon has accomplished most of his work in colonial Algeria through an ambitious housing program (1953-1959) then in independent Algeria through tourist architecture that has affected the whole of the territory (1966-1983), his works are just beginning to be rehabilitated by the authorities but he is highly regarded in academia (See Figure 8).

Fernand Pouillon said "When I touched on this Algerian tourist program, in a climate that I like, because I am Mediterranean, and when I saw what we could do, I changed my nature. First I adapted to Islam. Then I adapted to the way of working that is to say in a total abandonment of the frame, [...] I worked more as a sculptor than as an architect. I tried to make a sculpture on a monumental scale. [...] you can only draw them with a gesture. Some things cannot be drawn on a geometric" [16]. 

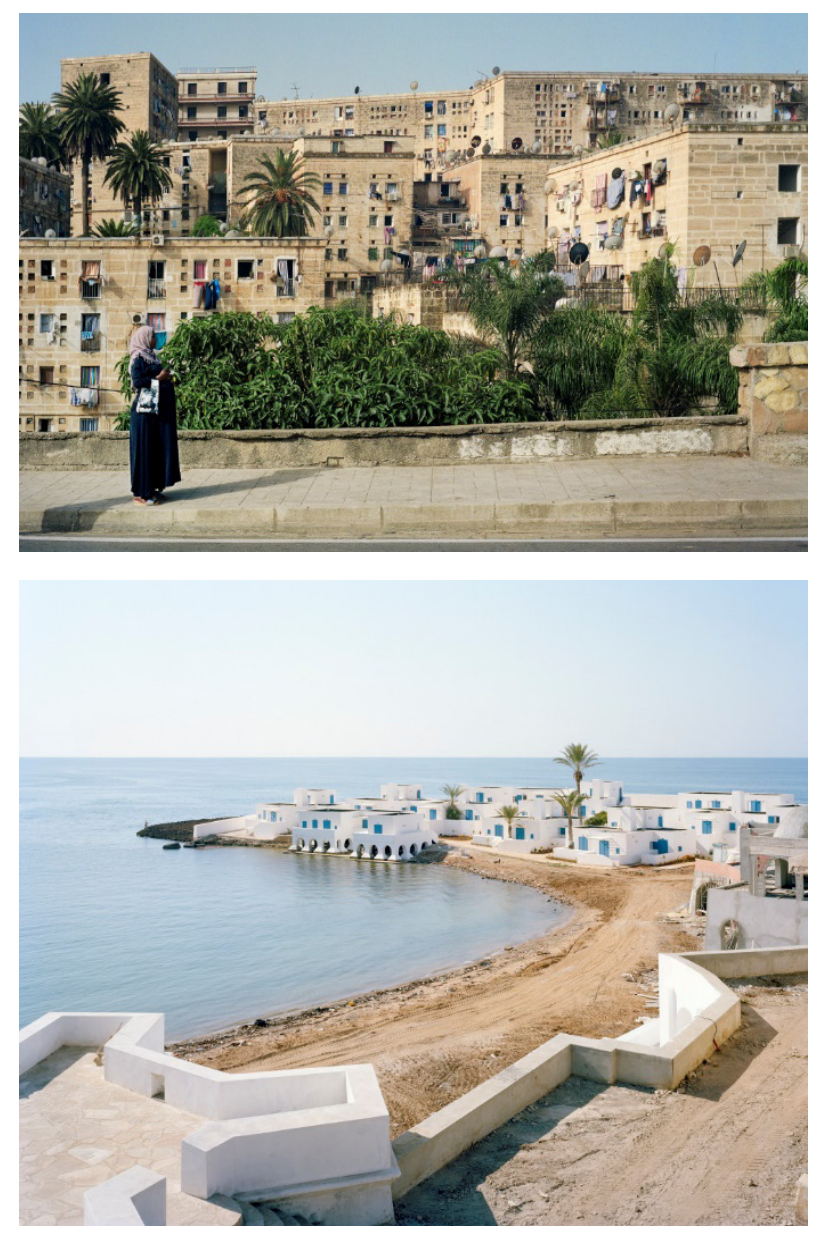

Figure 8. (a) L'Attente, Diar-el-Mahçoul 1954, Algiers, 2018 C Daphné Bengoa / (b) Tourist complex, Tipasa-Club 1971, Tipasa, 2018 (C) Leo Fabrizio
When they are introduced to the course and the works of this architect, students consider his approach and his prolific work as a treatise on Algerian architecture, tinged with backward glances and progressive interpretation. They see its architecture as a pan-Euro-Mediterranean form of expression, linking the elements of a local architecture to a modernizing vision yet at odds with the modernist doxa of the clean slate. Pouillon offers a vernacular approach without falling into the truisms, where stone replaces glass and concrete. He proclaims himself "Arab" and Algerian at heart, a speech that reinforces the students' inclination towards this extravagant architect who responds to their desire to belong (Figure 9).

Much more balanced, André Ravereau and his quest for preservation and purism exercised exclusively in historic sites [17] or Jean-Jacques Deluz and his literary production and his teaching are also, to a lesser extent, means of intellectualization of the student's approach. The most meticulous references evoke Hassan Fathy and his work Gourna, a Tale of two villages from 1969.

\section{Conclusions}

Talking about Algerian architecture is not easy in the Algerian professional environment as the current production is disparate and, unfortunately, without a quest for quality and identity. Political and economic conditions push for frenzied and greedy production where quality is rarely a question. It is up to the university to ask the question of the architectural style which emerges in the urban space and which will condition for years the relationship of the inhabitants to their environment.
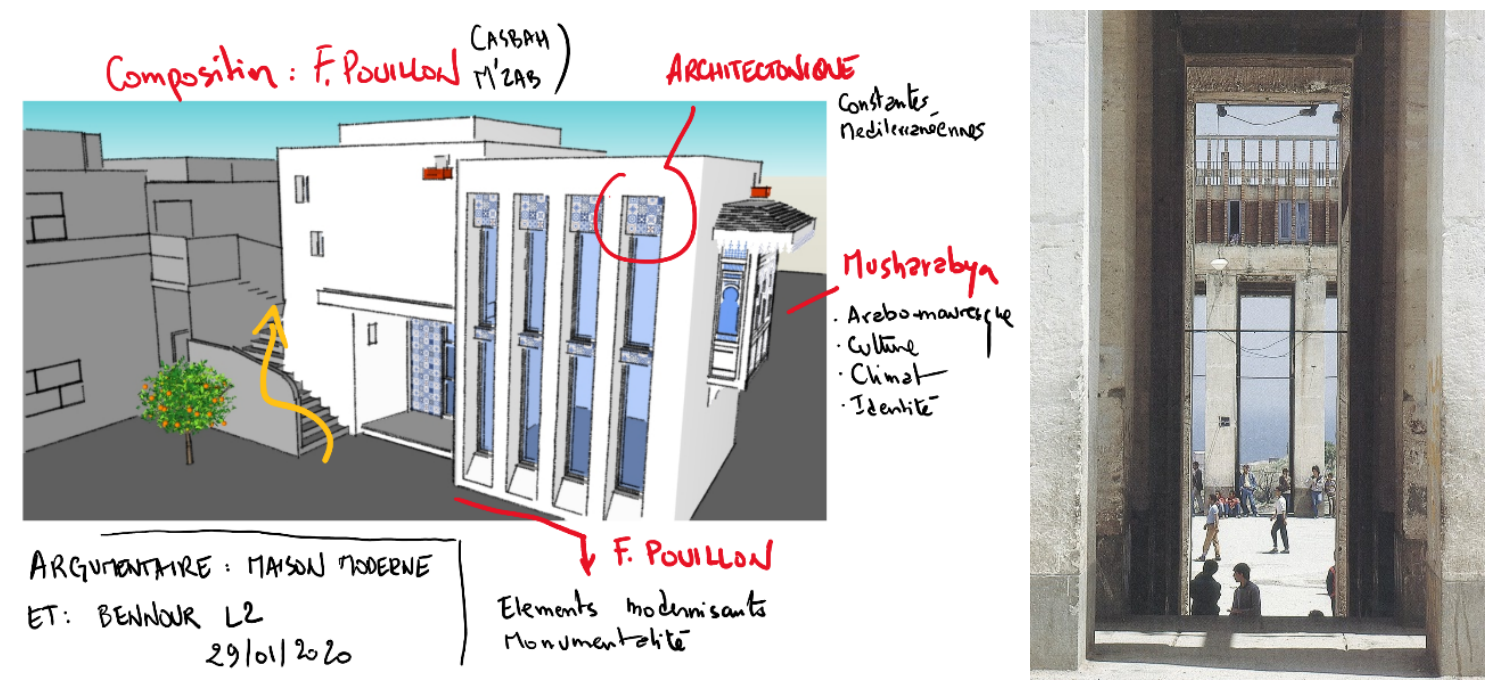

Figure 9. Extract from the logbook, argument for intermediate housing in second year with clearly displayed references for Fernand Pouillon. We notice an attempt at modernizing expression by assembling elements from the past (musharabya, casbah composition, gargoyles) and common Mediterranean elements (white colour, orange tree, interlocking volumetry). The monumentality of the facade alludes to Climat de France, the city of Pouillon built in 1957 in Algiers / Photo taken from the entrance to the Cité Climat de France in Algiers, built in 1957 by Pouillon. 
Our observation of students in the full expression of their visions of belonging to an Arab-Berber culture, to a Mediterranean territory, to a complex history mixing different ethnic groups and different influences, allowed us to understand the levers of formalization of the bias.

These are articulated around three axes: the search for adhesion to an identity (desire to belong), the quasi-physical response to the geo-climatic data (allusion to a Mediterranean unit) and the backing to a reference of scholarly legitimation. This results in a behavioural process that is more than introspective, taking charge of the student's relationship to the determining elements of the aforementioned levers to the detriment of a meta-method, in other words, a reflective approach.

Thus, the artefact wanted as an expression of Algerian architecture is the product of an addition of physical elements mainly from Arab-Moorish architecture to which the students will reserve an abstracting treatment to reduce its strong connotation. It will be a question of expressing in a contemporary way element that are after all classic and secular. Geographically, belonging to the Mediterranean basin justifies resorting to disparate solutions under the guise of climatic unity and cultural similarities. The use of semantic units such as the patio, the colour white and the tiered composition reflects this stereotypical approach.

Finally, the approach is justified by a reading of the written and architectural works of certain great figures of Algerian architecture but without this being framed and provided with scientific rigour.

However, is it scientific rigour that students need in developing what could be the expression of a viscerally Algerian, or Maghrebian, or Mediterranean architecture?

It is above all a matter of supporting them in the dialectical relationship between the past and the present, between Algeria as a nation and the Mediterranean as a common culture, to contribute to the emergence of a local and innovative expression, which embraces traditional visions without, however, succumbing to banal historicism or nostalgia.

Thus, the use of tradition is not perceived in our observations of behavior as a reaction to modernity or as an antithetical approach [18], but rather as a discourse of otherness. A discourse of authenticity as described by AlSayyad, but whose hyperconsumption makes the connection with the "real" fundamentally "displaced" and disembodied.

\section{REFERENCES}

[1] Corbin, J. M., \& Strauss, A. L. (2015). Basics of qualitative research: Techniques and procedures for developing grounded theory (Fourth edition). SAGE. ISBN: 978-1-4129-9746-1

[2] Couwenbergh, J.-P., \& Godyns, J. (2014). Concevoir l'architecture: Entre complexité et simplexité : L'exercice de la pensée, des chemins d'espace (dans une faculté d'architecture) [Designing the architecture: between complexity and simplicity. The exercise of thought, paths of space (in a faculty of architecture)]. In J.-L. Petit \& A. Berthoz (Eds.), Complexité-Simplexité. Collège de France. http://books.openedition.org/cdf/3379 ISBN: 978-2-7226-0 $330-1$

[3] Glaser, B. G. (1978). Theoretical Sensitivity: Advances in the Methodology of Grounded Theory. Sociology Press. ISBN: 978-1-884156-01-4

[4] Glaser, B. G., \& Strauss, A. L. (1967). The Discovery of Grounded Theory: Strategies for Qualitative Research. Aldine Publishing Company. ISBN: 978-0-202-30028-3

[5] DeWalt, K. M., \& DeWalt, B. R. (2011). Participant observation a guide for fieldworkers. Rowman \& Littlefield. ISBN: 9780759119277

[6] Bernard, H. R. (2013). Social research methods: Qualitative and quantitative approaches (2nd ed). SAGE Publications. ISBN: 978-1-4129-7854-5

[7] St John, W., \& Johnson, P. (2000). The Pros and Cons of Data Analysis Software for Qualitative Research. Journal of Nursing Scholarship, 32(4), 393-397.https://doi.org/10.111 $1 / j .1547-5069.2000 .00393 . x$

[8] Creswell, J. W. (2007). Qualitative inquiry and research design: Choosing among five approaches, 2nd ed (pp. xvii, 395). Sage Publications, Inc. ISBN: 978-1-4129-1607-3

[9] Vollstedt, M., \& Rezat, S. (2019). An Introduction to Grounded Theory with a Special Focus on Axial Coding and the Coding Paradigm. In G. Kaiser \& N. Presmeg (Eds.), Compendium for Early Career Researchers in Mathematics Education (pp. 81-100). Springer International Publishing. https://doi.org/10.1007/978-3-030-15636-7_4

[10] Atlas.ti. (2018). ATLAS.ti Scientific Software Development GmbH (8.4.22.0) [Windows]. ATLAS.ti Scientific Software Development GmbH. https://atlasti.com/

[11] Pagés Madrigal, J. M. (2020, October 24). MED-HERITAGES: Three Gazes [Webinar]. https://fb.wat $\mathrm{ch} / 1 \mathrm{k} 7 \mathrm{DIGiSRD} /$

[12] Logan, W. S. (2007). Closing Pandora's Box: Human Rights Conundrums in Cultural Heritage Protection. In $\mathrm{H}$. Silverman \& D. F. Ruggles (Eds.), Cultural Heritage and Human Rights (pp. 33-52). Springer. https://doi.org/10.100 7/978-0-387-71313-7_2

[13] Hoskins, J. (2010). Seeing syncretism as visual blasphemy: Critical eyes on caodai religious architecture. Material Religion, 6(1), 30-58. https://doi.org/10.2752/174322010X 12663379393332

[14] Ylimaula, A.-M. (1992). Origins of style: Phenomenological approach to the essence of style in the architecture of Antoni Gaudi, C. R. Mackintosh and Otto Wagner. Univ. of Oulu. ISBN: 978-951-42-3330-2

[15] In french : Bekkouche, A. (2008). Pour une architecture Algérienne [For an Algerian architecture]. In M. Haddab \& N. Remaoun-Benghabrit, L'Algérie 50 ans après. Etat des savoirs en sciences sociales et humaines 1954-2004 [Algeria 50 years later. State of knowledge in social and human sciences 1954-2004] (pp. 503-513). Editions C.R.A.S.C. 
ISBN: 978-9961-813-33-1

[16] In French: Maachi Maïza, M. (2008). L'architecture de Fernand Pouillon en Algérie [Fernand Pouillon's architecture in Algeria]. Insaniyat / إنسانيات. Revue algérienne d'anthropologie et de sciences sociales [Algerian journal of anthropology and social sciences], 42, 13-26. https://doi.org/10.4000/insaniyat.6707
[17] In french : Ravéreau, A., Baudouï, R., Potié, P., \& Picon, A. (2003). André Ravéreau: L'atelier du désert. [André Ravéreau: the desert workshop] Parenthèses. ISBN: 978-2-86364-120-0

[18] AlSayyad, N. (2014). Traditions: The 'real', the hyper, and the virtual in the built environment. Routledge/Taylor \& Francis Group. ISBN-13: 978-0415777735 